\title{
Efficacy, safety, and patient acceptability of the etonogestrel and ethinyl estradiol vaginal ring
}

This article was published in the following Dove Press journal:

Open Access Journal of Contraception

10 July 2014

Number of times this article has been viewed

\section{Iñaki Lete \\ Maialen Pérez de Arrilucea \\ María Rodríguez \\ Eskerne Bello}

Department of Gynecology, University Hospital Araba, Vitoria, Spain
Correspondence: Iñaki Lete Servicio de Ginecología Hospital Universitario Araba, Vitoria 01009, Spain Tel +34945007017

$\mathrm{Fax}+34945007901$

Email luisignacio.letelasa@osakidetza.net
Abstract: The contraceptive vaginal ring (CVR) is a combined hormonal contraceptive method, containing ethinyl estradiol and etonogestrel, that works by inhibiting ovulation. It differs from combined oral contraceptives (COCs) in the route of administration, which is vaginal, and the frequency of administration, which is monthly. The efficacy of the CVR is similar to that of COCs but compliance appears to be better in typical users. The CVR enables appropriate control of the menstrual cycle, with a similar side effect profile to COCs, while achieving good user acceptance. Different studies have established noncontraceptive beneficial effects of the CVR; for example, it can be useful for treating dysmenorrhea or excess menstrual bleeding. Recent epidemiological studies have confirmed that the risk of venous thromboembolism with the CVR is similar to that of COCs, including COCs that contain levonorgestrel.

Keywords: contraceptive vaginal ring, efficacy, cycle control, acceptability, safety

\section{Introduction}

A vaginal ring to deliver steroid hormones was first described in $1970 .{ }^{1}$ The device comprised a silicone rubber ring impregnated with medroxyprogesterone and was developed as a contraceptive. Currently, there are two different types of vaginal ring: those with a sandwich arrangement, and the so-called reservoir intravaginal rings. Vaginal rings that release ethinyl estradiol (EE) and etonogestrel (ENG) belong to the group of reservoir devices. Steroid hormones are dispersed or dissolved in a central core, surrounded by an external membrane of drug-free polymer; in this case, ethylene vinyl acetate (EVA), a polymer obtained by adding vinyl acetate to polyethylene. The material has the advantages of greater flexibility, adhesion, and resistance to tearing, and has been widely used in other medical and pharmacological applications. ${ }^{2}$ A pharmacological study that analyzed the diffusion and solubility coefficients of steroid substances dissolved in an EVA core concluded that EVA was an appropriate substrate for developing controlled release systems for certain steroid hormones, in particular, EE and ENG. ${ }^{3}$

The matrix of this ring contains ENG $(11.7 \mathrm{mg})$, which is the active metabolite of the progestogen desogestrel (DSG), and EE $(2.7 \mathrm{mg})$, uniformly distributed throughout. It releases $15 \mu \mathrm{g}$ of EE and $120 \mu \mathrm{g}$ of ENG daily.

The ring has an outer diameter of $54 \mathrm{~mm}$ and a cross-sectional diameter of $4 \mathrm{~mm}$. This size was chosen after studying different ring sizes (with $3 \mathrm{~mm}, 3.5 \mathrm{~mm}$, and $4 \mathrm{~mm}$ cross-sectional diameters); the ring with the largest cross-sectional diameter was found to be the most appropriate one to use. ${ }^{4}$ In October 2001, the US Food and 
Drug Administration approved the vaginal ring as a new combined hormonal contraceptive (CHC) method, and the product was marketed under the name NuvaRing ${ }^{\circledR}$ (Organon, Oss, the Netherlands). The NuvaRing is designed to be used for 3 weeks, followed by a hormone-free week. Like other $\mathrm{CHCs}$, such as combined oral contraceptives (COCs), the ring acts by inhibiting ovulation. ${ }^{5}$ Vaginal rings differ from COCs in their administration regimen, which is monthly, and the route of administration, which is vaginal.

The capacity of the vagina to absorb different drugs was first reported in $1918 .{ }^{6}$ The drugs then studied were morphine, atropine, and potassium iodide, among others. Subsequently, the possibility of delivering other drugs vaginally has been demonstrated. Examples include indomethacin, ${ }^{7}$ bromocriptine, ${ }^{8}$ and misoprostol. ${ }^{9}$ For almost 30 years, we have known that the hormones in certain COCs can be administered vaginally without losing any contraceptive efficacy. ${ }^{10}$ More recently, this route of administration has been shown to be feasible for the delivery of steroid hormones used in hormone replacement therapy. ${ }^{11}$ Current knowledge of the vagina suggests that this organ is appropriate for administration of many different drugs; in particular, for the administration of steroid hormones. ${ }^{12}$

\section{Pharmacokinetics of the vaginal ring contraceptive}

In a randomized, crossover clinical trial of 16 healthy volunteers who used the vaginal contraceptive, for a single cycle, and a COC with DSG and EE for a single cycle, the bioavailability of ENG was $102.9 \%$, when administered vaginally, and $79.2 \%$ when administered orally. The bioavailability of EE was similar for the two formulations studied. ${ }^{13}$ The substantial bioavailability of the gestagen component of the contraceptive confers a high contraceptive efficacy through suppression of ovarian activity. In a randomized study that compared the effects on follicular diameter, endometrial thickness, and plasma levels of follicle stimulating hormone (FSH), luteinizing hormone (LH), 17 $\beta$-estradiol, and progesterone of a vaginal ring releasing $15 \mu \mathrm{g} /$ day of EE and $120 \mu \mathrm{g} /$ day of ENG, against an oral contraceptive comprising $30 \mu \mathrm{g}$ of EE and $150 \mu \mathrm{g}$ of levonorgestrel (LNG), the two contraceptive formulations were found to adequately suppress ovarian activity. ${ }^{14}$

In a study by Timmer and Mulders, ${ }^{13}$ the authors reported that plasma concentrations of ENG increased during the first week of use of the vaginal ring and subsequently gradually decreased, remaining above the threshold for inhibition of ovulation for 5 weeks. The mean concentration of ENG at the end of the first week of use of the vaginal ring $(1,578 \mathrm{ng} / \mathrm{L})$ was similar to the mean steady-state plasma concentration of ENG in the oral contraceptive group $(1,617 \mathrm{ng} / \mathrm{L})$. Thus, the oral contraceptive group showed mean concentrations comparable with the maximum concentration attained in the ring group. In the case of EE, the same study showed that the plasma concentration reached a peak at 2-3 days after ring insertion, and then decreased at a rate of $0.77 \mathrm{ng} / \mathrm{L}$ per week. The $\mathrm{C}_{\max }$ of EE during ring use was $70 \%$ lower than during oral contraceptive use. As in the case of ENG, EE peaks occurred only once per cycle with use of the vaginal ring, whereas a daily peak occurs with oral contraception. The final conclusion of the authors is that systemic exposure to ENG is similar between the vaginal ring and oral contraceptive. But, in the case of EE, exposure with the vaginal ring is $50 \%$ lower than the exposure with the oral contraceptive.

Ovarian activity was investigated in two pharmacokinetic studies, using ultrasound measurement of follicular diameter and determination of FSH, LH, and 17 $\beta$-estradiol levels. In one study, ovulation was inhibited in all individuals who used the vaginal ring correctly. ${ }^{5}$ The other study analyzed the effect of the ring on ovulation when insertion was delayed after the hormone-free week. ${ }^{15}$ Ovarian follicles were measured by transvaginal ultrasound. When the maximum diameter of $13 \mathrm{~mm}$ was reached (mean: 11 days), the vaginal ring was inserted. The authors reported inhibition of ovulation in all cases. These studies confirm the efficacy of the vaginal ring, even in situations of suboptimal compliance.

\section{Efficacy}

The efficacy of the vaginal ring was investigated in a prospective, multicenter, open-label, non-comparative study with 13 cycles of follow-up in 2,322 women who completed 23,298 cycles (1,786 woman-years). In total, 21 pregnancies occurred (Pearl Index: 1.18; 95\% confidence interval [CI]: 0.73-1.80). Eleven of these pregnancies were attributed to poor compliance, and the Pearl Index for the population who correctly used the contraceptive (per-protocol population) was 0.77 (95\% CI: $0.37-1.40) .{ }^{16}$

In 2005 , the results of a phase III study that compared the vaginal ring with a COC containing $150 \mu \mathrm{g}$ of LNG and $30 \mu \mathrm{g}$ of EE were published. In the trial, 1,030 women were randomized (512 to the vaginal ring group and 518 to the COC group) and followed-up for 13 cycles. Five pregnancies were reported in each group, giving a Pearl Index in the intention-to-treat analysis of 1.23 (95\% CI: 0.40-2.86), for the ring, and 1.19 (95\% CI: 0.39-2.79) for the COC. The Pearl Index in the per-protocol analysis was $0.71(95 \%$ 
CI: 0.00-1.52) and 0.43 (95\% CI: 0.00-1.01), respectively. ${ }^{17}$ Another randomized clinical trial compared the efficacy of the vaginal ring with that of a COC containing $30 \mu \mathrm{g}$ of EE and $3 \mathrm{mg}$ of drospirenone. A total of 983 women were randomized (499 to the ring group and 484 to the COC group). Follow-up lasted 13 cycles, during which time there was one pregnancy in the ring group (Pearl Index: 0.25; 95\% CI: 0.006-1.363) and four pregnancies in the COC group (Pearl Index: 0.99; 95\% CI: 0.269-2.530). ${ }^{18}$

Efficacy with ideal use of the vaginal ring is very high, ${ }^{19}$ but drops off in typical users, in whom a failure rate of $9 \%$ woman-years was reported in the general population in the United States, during the first year of use. ${ }^{20}$ The difference between the ideal and real indices was attributed to poor compliance.

In a cross-sectional study of 26,150 women in Spain who were currently using a $\mathrm{CHC}$, noncompliant behavior (missed or delayed administration or, in the case of the ring and patches, delays in removal) was reported by $71 \%$ of pill users, $32 \%$ of patch users, and $21.6 \%$ of vaginal ring users $(P<0.0001) .{ }^{21}$ The conclusion was that compliance in typical users is better with monthly regimens (vaginal ring) than with daily regimens (COCs), and so we might expect a better real-world effectiveness for the vaginal ring.

A recent position paper of the Spanish Society of Contraception determined the Pearl Index to be 2.1 for typical COC users, and 1.23 for typical vaginal ring users. ${ }^{22}$ Although some data hint at a greater effectiveness for the vaginal ring (thanks to better compliance), given the substantial differences observed between studies in the United States and Europe, a large prospective study is needed, to compare the effectiveness of the vaginal ring with that of the COCs, with collection of compliance data during the study period.

\section{Bleeding pattern}

Good cycle control during hormonal contraceptive use is one of the keys for ensuring continuity of use. In 1995, Rosenberg et $\mathrm{al}^{23}$ published a review of the factors that affect compliance and continuity of use of COCs. The authors estimated a relative risk of 1.8 for stopping taking the pill when intermenstrual bleeding occurs.

The cycle control afforded by the vaginal ring has been analyzed in at least four comparative, randomized clinical trials. In one of these, the ring was compared with an oral contraceptive containing $30 \mu \mathrm{g}$ of $\mathrm{EE}$ and $3 \mathrm{mg}$ of drospirenone. ${ }^{24}$ In two studies, the comparator was an oral contraceptive with $30 \mu \mathrm{g}$ of EE and $150 \mu \mathrm{g}$ of LNG. ${ }^{25,26}$ In the other study, the ring was compared with two different pills, one with $20 \mu \mathrm{g}$ of EE and $100 \mu \mathrm{g}$ of LNG, and the other with $15 \mu \mathrm{g}$ of EE and $60 \mu \mathrm{g}$ of gestodene. ${ }^{27}$ The percentage of women with intermenstrual bleeding in the four studies ranged from $1.1 \%-9.5 \%$, in the ring groups, and from $3.5 \%-35.8 \%$ in the pill groups. In the four studies, better cycle control was achieved in the ring groups, even when compared with pills that delivered twice the daily EE dose.

\section{Side effects}

Given that the vaginal ring is a $\mathrm{CHC}$, it has some of the same side effects as COCs; in particular, estrogen-dependent ones. In addition, there are some side effects that are specific to the route of administration.

In a prospective, 1-year study that included 2,322 women who were starting use of the vaginal ring, the incidence of estrogen-related side effects was low: nausea was reported in $2.8 \%$, breast tension in $1.9 \%$, and headache in $6.6 \%$ of subjects. ${ }^{28}$ In this same sample of women, 5\% reported leukorrhea and $6 \%$ reported vaginitis. ${ }^{16}$ The continuation rate for the ring was $64.6 \%$ at the end of the study. The reasons for discontinuation, in the $35.4 \%$ of women who stopped using the ring, included side effects and reasons unrelated to the contraceptive method. In the same study, the rate of ring expulsions was $4 \%$.

In general, it can be affirmed that, compared with COCs, the rate of side effects is lower for the vaginal ring (in particular, of estrogen-dependent reactions), whereas local vaginal effects are more frequent. ${ }^{17}$

In a comparative study of three different types of contraception (vaginal ring, pill with $\mathrm{EE} / \mathrm{LNG}$, and pill with EE/gestodene), which included 280 women, irritability and depression were less frequent among ring users after 3 cycles. ${ }^{27}$ In another randomized clinical trial, in which the ring was compared against an EE- and drospirenonecontaining $\mathrm{COC}$, the authors found less emotional lability among ring users. ${ }^{29}$

One of the main concerns of women before starting to use a hormonal contraceptive method is the potential impact on body weight. In a prospective study, with 13 cycles of follow-up, the mean increase in weight of participating women was $0.43 \mathrm{~kg}{ }^{16}$

In a clinical trial, also with 13 cycles of follow-up, which compared the vaginal ring against a pill containing $30 \mu \mathrm{g}$ of $\mathrm{EE}$ and $3 \mathrm{mg}$ of drospirenone, the primary objective was to assess the impact of these contraceptives on body weight. No statistically significant differences were reported between the two treatment arms, and the authors concluded that the 
effect of the vaginal ring on body weight was similar to that exercised by the COC with drospirenone. ${ }^{24}$

Different studies have concluded that use of the vaginal ring is associated with local side effects in the vagina, the most frequent being leukorrhea and vaginitis. ${ }^{30}$ However, a recent review of the possible local effects of the vaginal ring concluded that the use of a CVR did not alter the vaginal ecosystem and, therefore, does not substantially affect vaginal health. ${ }^{31}$

\section{Beneficial noncontraceptive effects Effect on dysmenorrhea}

Primary dysmenorrhea is defined as menstrual pain in the absence of other diseases, and is linked to excessive production of prostaglandins by the menstrual endometrium. Given its high incidence and significant associated limitations to quality of life, the condition is important. For years, it has been known to respond favorably to the inhibition of ovulation. ${ }^{32}$

In view of the etiology of primary dysmenorrhea, ovulation inhibitors have been proposed as a potential therapeutic option. ${ }^{33}$ Bearing in mind that the mechanism of action of the vaginal ring contraceptive, like other combined hormonal methods, is inhibition of ovulation, beneficial effects on dysmenorrhea might be expected.

Five European studies, all with similar data collection methods, have investigated the impact of use of the vaginal ring on primary dysmenorrhea. The first of these studies (in chronological order) was a Spanish study. ${ }^{34}$ Subsequently, two Swiss studies, ${ }^{35,36}$ a German study, ${ }^{37}$ and a Czech study ${ }^{38}$ have been published. These five studies collected data from new vaginal ring users. One of the parameters analyzed was improvement in dysmenorrhea. Of the 12,457 women enrolled, 4,418 (35.4\%) had dysmenorrhea before starting to use the vaginal ring. After 6 cycles of ring use, only 1,370 women $(10.9 \%)$ still had dysmenorrhea; that is, $69 \%$ of the women who presented dysmenorrhea improved in the first few cycles of vaginal ring use.

The effect of the ring on dysmenorrhea was also investigated in a clinical trial in which women switched from a $\mathrm{COC}$ to either a ring or a patch. When changing to a non-daily $\mathrm{CHC}$ method, more women who switched to the patch (compared with those who switched to the CVR) experienced increased dysmenorrhea (29\% versus $16 \%)$, frequent nausea ( $8 \%$ versus $1 \%$ ), and frequent mood swings $(14 \%$ versus $8 \%) .{ }^{39}$ In the first three months of a Dutch study, the percentage of women with dysmenorrhea decreased from $42 \%$ to $26 \%(P<0.0001)$. The percentage of women with premenstrual complaints dropped from $45 \%$ to $29 \%{ }^{40}$

\section{Decrease in volume of menstrual bleeding}

Heavy menstrual bleeding, or menorrhagia, is defined as bleeding of more than $80 \mathrm{cc}$, at regular intervals, without any associated diseases. This benign condition is often associated with iron-deficiency anemia, and may affect as many as $30 \%$ of women.. ${ }^{41}$ The Spanish Etn@ (ETonogestrel en Anticoncepción) study was a prospective study that included 805 new users of the vaginal ring, and analyzed both the duration and severity of menstrual bleeding among ring users. ${ }^{34}$ After 3 cycles of use, the duration and severity of bleeding decreased, with $50 \%$ of women describing their bleeding as mild.

More recently, a randomized clinical trial, in which 95 women with heavy menstrual bleeding were assigned to use either the vaginal ring or treatment with norethisterone (at a dose of $15 \mathrm{mg} /$ day from the fifth to the 26th days of the cycle, for 3 cycles), did not find any significant differences in hemoglobin levels between the two treatment arms. ${ }^{42}$ The investigators concluded that, although both options are effective at reducing the extent of menstrual bleeding, the advantage of the ring is that it provides protection against pregnancy.

\section{Improvement in premenstrual symptoms}

Premenstrual syndrome (PMS) encompasses a wide range of physical and emotional symptoms that become manifest from 2 weeks prior to menstruation and end shortly after the start of the menstrual period. A recent survey of a representative sample of Spanish women of fertile age found that, although moderate or severe PMS affects a relatively low percentage of women $(8.9 \%), 73 \%$ of women showed premenstrual symptoms that could be classified as mild. ${ }^{43}$ The etiology of PMS is not entirely known, but it is accepted that premenstrual symptoms are associated with progesterone produced by the corpus luteum. Thus, inhibition of ovulation has been one of the therapeutic strategies used. ${ }^{44} \mathrm{CHC}$ is often used to control the symptoms associated with PMS. In a Spanish study, $94.8 \%$ of the women who sought medical attention for premenstrual symptoms requiring pharmacological treatment were prescribed $\mathrm{CHC} .{ }^{45}$ Given that the mechanism of action of the vaginal ring is the same as the COC (ie, inhibition of ovulation), the five European studies mentioned above ${ }^{34-38}$ analyzed possible beneficial effects of the vaginally administered contraceptive on premenstrual symptoms. Of the 12,457 women enrolled, 5,219 (41.9\%) 
had mild premenstrual symptoms before starting to use the vaginal ring. After 6 cycles of ring use, only 1,669 women (13.4\%) still had such symptoms; that is, $68 \%$ of women with premenstrual symptoms will improve in the first cycles of vaginal ring use.

\section{Beneficial effects related to sexuality}

The first benefit of the pill, when it came onto the market in the 1960s, was to separate reproduction from sexual experience, thereby opening the way to risk-free enjoyment of sexuality, which is now considered a fundamental human right.

Nevertheless, there are contradictory data on the influence of hormonal contraception on the sexual life of users. Some studies have shown that women who take contraceptive pills have more frequent sexual relations and more intense orgasms than those who use other contraceptive methods, ${ }^{46}$ whereas other studies conclude that oral contraceptives have a negative impact on libido and decrease the frequency of sexual relations. ${ }^{47}$ With the aim of assessing the impact of vaginal ring use on the sexuality of users, a clinical trial was conducted in 51 sexually active, healthy women with stable partners. These women were randomized to one of two treatments: 26 women used the vaginal ring and 25 used a COC with $20 \mu \mathrm{g}$ of EE and $150 \mu \mathrm{g}$ of DSG. In addition, 25 women, who did not use either of these methods, were included as a control group. ${ }^{48}$ The effects of the hormonal preparations were assessed though the Interviewer Ratings of Sexual Function ${ }^{49}$ after 3 and 6 cycles of use. The women who used the vaginal ring had significantly more sexual fantasies, as a result of a greater psychological impact on them and their partners.

In another randomized, prospective study lasting 1 year, the effects of the ring on sexual activity were compared with those of two different oral contraceptives (one with $20 \mu \mathrm{g}$ of EE and $100 \mu \mathrm{g}$ of LNG, the other with $15 \mu \mathrm{g}$ of EE and $60 \mu \mathrm{g}$ of gestodene) in a sample of 280 women. ${ }^{27}$ Among users of the vaginal ring, there were more subjects who reported better vaginal lubrication and, as a result, greater sexual satisfaction.

A recent randomized clinical trial, in which the impact on parameters of sexuality and vascularization of the clitoris were compared for 21 women treated with a COC (30 $\mu \mathrm{g}$ of EE and $3 \mathrm{mg}$ of drospirenone), against 19 women treated with the vaginal ring, concluded that 6 months of treatment with either type of hormonal contraception was associated with a lower score on the McCoy Female Sexuality Questionnaire. ${ }^{50}$ However, the frequency of sexual intercourse and frequency of orgasm during intercourse decreased among
COC users only, who also experienced increased pain during intercourse.

\section{Treatment of acne}

Hormonal treatment of acne includes the use of combined contraceptives that increase circulating levels of sex hormone binding globulin (SHBG), which reduces the levels of testosterone, and the use of antiandrogenic substances that compete at a cell receptor level. ${ }^{51} \mathrm{~A}$ Cochrane review, which identified 23 clinical trials, concluded that oral contraceptives containing chlormadinone acetate or cyproterone acetate show a more notable improvement in acne than contraceptives with LNG and desogrestrel. ${ }^{52}$

In the Etn@ study, ${ }^{34}$ which included 805 Spanish women starting use of the vaginal ring, $18.7 \%$ had mild or moderate acne on enrollment. After 6 cycles of vaginal ring use, the percentage of individuals with acne decreased to $7.2 \%$ $(P<0.005)$. The authors concluded that the CVR has a positive effect on women with mild or moderate acne.

\section{Effects on bone density}

All hormonal contraceptives suppress (to greater or lesser extent) estrogen production by the ovaries, such that an effect on bone density is biologically plausible. In the case of CHCs containing estrogens and gestagens, suppression of the endogenous production of estradiol may be compensated by exogenous delivery of EE. This is clearly not the case when contraceptives comprising gestagens alone are used.

In 2005, the results of an open-label, multicenter trial were published. This trial was designed to assess the impact of vaginal ring use on bone mineral density (BMD) ${ }^{53}$ in 144 patients, randomized to use the vaginal ring $(n=105)$ or a non-hormonal contraceptive method $(n=39)$. Patients underwent bone densitometry measurements (dual-energy X-ray absorptiometry) at 12 and 24 months of follow-up. The results demonstrated that, at 2 years, there were no significant changes in BMD among women who used the vaginal ring.

Subsequently, in 2010, the findings were published of a randomized trial that compared the effects of the vaginal ring and a contraceptive patch on BMD in 60 women, with follow-up lasting 12 months. ${ }^{54}$ No significant modifications were found in bone remodelling in any of the groups studied.

\section{Drug-drug interactions}

The contraceptive ring should be used vaginally. Although, in more than $70 \%$ of cycles, withdrawal bleeding occurs during 
the week when the ring is not used, ${ }^{24}$ a significant number of women will need to combine use of the vaginal ring with that of a tampon. With the aim of investigating the effect of tampon use on the pharmacokinetics of ENG and EE released by the vaginal ring, a randomized, crossover study investigated the area under curve (AUC), for both steroids, in a cycle of vaginal ring use, and in another cycle, in which (in addition to the vaginal ring) the participants used four tampons per day for 3 consecutive days, starting on Day 8 of the study cycle. ${ }^{55}$ The results of this study showed that tampon use at the same time as vaginal ring use did not have any effect on the serum concentrations of ENG and EE. Therefore, no interactions, in terms of hormone absorption in the vagina, were detected when tampons were used.

Vaginal candidiasis may occur relatively often during ring use. ${ }^{56}$ Two randomized studies have investigated the effect of several antimycotic formulations on systemic exposure to EE and ENG released by the vaginal ring. ${ }^{57}$ The results of these studies showed that simultaneous administration of miconazole nitrate slightly increased the systemic exposure to steroids released by the vaginal ring, and this increase appeared to be related to a greater release of these steroid hormones from the vaginal ring. However, this increased hormonal release does not seem to compromise the effectiveness of the contraceptive method.

Likewise, another two pharmacokinetic studies have demonstrated the absence of interactions between EE and ENG (released by the vaginal ring) and amoxicillin and doxycycline, administered orally. Thus, the efficacy of the ring is not compromised when using these types of antibiotics. ${ }^{58}$ Some women may wish to use two contraceptive methods at once, consisting, in this case, of concomitant use of the vaginal ring with a barrier method. Among the barrier methods available, the condom is the most widely-used, and many condoms are impregnated with spermicide. The effects of nonoxinol-9, a widely used spermicide, on the release and absorption of EE and ENG were studied in 12 women for 2 cycles. No pharmacological interactions were found between nonoxinol-9 and the steroid hormones released by the vaginal ring. Thus, the authors of the study concluded that the efficacy of the vaginal ring was not compromised when used concomitantly with this spermicide..$^{59}$ Recently, a report was published of a possible influence of ENG, released by the vaginal ring, on urinary measurements of free cortisol in a patient with Cushing syndrome. ${ }^{60}$ The clinical implications of these findings are that administration of these steroids should be avoided in the days prior to measurement of cortisol, in users who are in follow-up for Cushing syndrome.

\section{Acceptability}

The acceptability of a given contraceptive method depends on many factors. The information available to the individual is one of the most important of these. In 2007, the results were published of a Spanish study of 9,700 women who started or restarted using a $\mathrm{CHC}$ method. These women were provided with structured information on the characteristics of each of the methods available: pill, patch, or ring. After receiving the information, $46 \%$ of the women chose the vaginal ring, $39 \%$ the COC, and $15 \%$ the patch. ${ }^{61}$ This study, known as the TEAM study, showed the need for providing complete and adequate information to women before prescribing any contraceptive method. Subsequent studies, performed in different European countries, have confirmed the preliminary data from the TEAM study, shown that the information facilitated may help women make decisions, and corroborated that the vaginal ring is a highly regarded option among users. ${ }^{62-68}$

One of the parameters that measures acceptability of a contraceptive method is the continuation rate. A prospective study, with follow-up lasting 12 cycles, enrolled 3,443 women who started using a $\mathrm{COC}$, patch, or ring. The continuation rate was $45.9 \%$ among COC users, $42.3 \%$ among ring users, and $26 \%$ among patch users. ${ }^{69}$ The conclusion was that the ring was not inferior to the COC in either continuity of use or effectiveness among typical users.

One factor that may have an impact on the acceptability of the vaginal ring is the possibility that the user may be aware of its presence during use and during sexual relations. This question has been addressed in several clinical studies. In a study by Dieben et al, ${ }^{16}$ the percentage of women who reported (at least occasionally) feeling the ring during intercourse was $18 \%$, while $32 \%$ of the partners of participants reported feeling the ring during intercourse. However, most partners had no objection to the participant's use of the ring.

In an article by Novak et al, ${ }^{70}$ which presented data from two non-comparative studies performed in Europe and the United States, with 2,322 women who started to use the vaginal ring, $84.8 \%$ of participants and $70.6 \%$ of their partners did not notice the ring during intercourse. In the Etn@ study, ${ }^{34}$ in which participants were asked about their perception of the ring, $80 \%$ of women and $75 \%$ of partners were unaware the ring. Of note is that only $4.5 \%$ of the partners of women objected to the ring usage when they noticed it during intercourse.

\section{Safety}

Combined hormonal contraception is known to increase the risk of venous thromboembolism (VTE). ${ }^{71}$ 
A recent epidemiological study of a Danish database found that, compared with users of COCs containing LNG, the adjusted relative risk of venous thrombosis in vaginal ring users was 1.9 (95\% CI: $1.3-2.7))^{72}$ According to these authors, the increase in risk of VTE was greater for non-oral $\mathrm{CHCs}$ that contained second-generation progestins.

The mechanism by which $\mathrm{CHC}$ use increases the risk of VTE has not been fully determined but it is known to be mediated by the impact of estrogen on coagulation factors. ${ }^{73}$

A clinical trial with 87 women, which compared the vaginal ring against a COC containing $30 \mu \mathrm{g} \mathrm{EE}$ and $150 \mu \mathrm{g}$ LNG for 6 cycles of treatment, found no differences in the majority of hemostatic parameters, except for an increase in the levels of factor VII and a greater activity of antithrombin III and protein $\mathrm{C}$ among ring users. ${ }^{74}$

A pharmacokinetic study in which the plasma levels and AUC of EE were compared amongst users of a COC with $30 \mu \mathrm{g}$ of EE, a patch that released $20 \mu \mathrm{g} /$ day of EE, and a ring that released $15 \mu \mathrm{g} /$ day of $\mathrm{EE}$, found that exposure to EE in the ring group was 3.4 times lower than in the patch group $(P<0.05)$ and 2.1 times lower than in the COC group $(P<0.05)$. The authors concluded that the contraceptive method with lowest exposure to estrogen is the vaginal ring. ${ }^{75}$

A study designed to assess the impact of the ring and the patch on certain markers of thrombosis, in which 143 female COC users were randomized to use the vaginal ring $(n=68)$ or the transdermal patch $(\mathrm{n}=75)$, did not find any changes in SHBG levels (-1.6 [95\% CI: $-16.6-13.5])$ in women who changed to the ring, while protein $\mathrm{S}$ increased significantly (+5.3\% [95\% CI: $1.1 \%-9.6 \%]) .{ }^{76}$ The activated protein C resistance ratio did not undergo a significant change from baseline (+0.02 [95\% CI: $-0.10-0.14])$. Laboratory data confirmed that use of the vaginal ring does not lead to significant changes in coagulation parameters suggestive of a greater risk of venous thromboembolism (VTE).

Recent epidemiological data further support this affirmation, contradicting the data from a Danish study by Lidegaard et al. ${ }^{72}$

The number of VTE events in new users of LNG-containing COCs was compared against that of new users of drospirenonecontaining COCs, norelgestromin-containing patches, and ENG rings, who were included in the databases of two health care programs in the United States. In total, data was analyzed from 860,087 women, aged $10-55$ years, who received at least one prescription of a study contraceptive between January 1, 2001 and December 31, 2007. The hazard ratio for VTE events in the comparison of vaginal ring with lowdose estrogen comparators among new users was 1.09 (95\% CI $0.55-2.16) .{ }^{77}$

More recently, the results of the TASC (The Transatlantic Active Surveillance on Cardiovascular Safety of NuvaRing) study have been published. ${ }^{78}$ This was a prospective, 4-year study in which 1,661 centers in the United States and Europe recruited 16,864 women in the ring group and 16,431 women in the COC group, providing a total of 66,489 women-years. The primary objective was to compare the risks of vaginal ring use with those of $\mathrm{COC}$ use.

During the follow-up period, 57 cases of VTE were reported: 19 among ring users, 26 among COC users, 11 among women who were not using any $\mathrm{CHC}$, and 1 among patch users. The estimated incidence of VTE events per 10,000 women-years was 8.3 for the vaginal ring, 9.2 for COC in general, and 7.8 for COCs with LNG. The differences were not statistically significant. The results show that the vaginal ring is not associated with an increased risk of VTE events, compared with other alternatives.

\section{Conclusion}

The contraceptive vaginal ring is a $\mathrm{CHC}$ method that works by inhibiting ovulation. It differs from combined COCs in the route of administration, which is vaginal, and the frequency of administration, which is monthly. The efficacy of the CVR is similar to that of COCs, but compliance appears to be better, in typical users. CVR enables appropriate control of the menstrual cycle, with a similar side effect profile to COCs, while achieving good acceptance by users. Different studies have established noncontraceptive beneficial effects of the ring; for example, it can be useful for treating dysmenorrhea or excess menstrual bleeding.

Recent epidemiological studies have confirmed that the risk of VTE with CVR is similar to that of COCs, including COCs that contain LNG.

\section{Acknowledgments}

Language assistance was provided by Dr Greg Morley of Pharmwrite SL, funded by Merck Sharp \& Dohme Corp (MSD), Spain.

\section{Disclosure}

Iñaki Lete is a member of the International Advisory Boards of MSD and Teva Pharmaceutical Industries Ltd (Teva). He has received fees for speaking at symposia sponsored by Bayer HealthCare AG, MSD, Teva, and HRA Pharma SA. 
The other authors report no conflicts of interest in this work. The authors alone are responsible for the content and the writing of this paper.

\section{References}

1. Dziuk P, Cook B. Passage of steroids through silicone rubber. Endocrinology. 1966;78(1):208-211.

2. Shastri PV. Toxicology of polymers for implant contraceptives for women. Contraception. 2002;65(1):9-13.

3. van Laarhoven JA, Kruft MA, Vromans H. In vitro release properties of etonogestrel and ethinyl estradiol from a contraceptive vaginal ring. Int J Pharm. 2002;232(1-2):163-173.

4. Roumen FJ, Dieben TO. Clinical acceptability of an ethylenevinyl-acetate nonmedicated vaginal ring. Contraception. 1999;59(1): $59-62$.

5. Mulders TM, Dieben TO. Use of the novel combined contraceptive vaginal ring NuvaRing for ovulation inhibition. Fertil Steril. 2001;75(5):865-870.

6. Macht DI. On the absorption of drugs and poisons through the vagina. J Pharmacol Exp Ther. 1918;10:509-522.

7. Abramov Y, Nadjari M, Weinstein D, Ben-Shachar I, Plotkin V, Ezra Y. Indomethacin for preterm labor: a randomized comparison of vaginal and rectal-oral routes. Obstet Gynecol. 2000;95(4):482-486.

8. Motta T, de Vicentiis S, Marchini M, Colombo N, D'Alberton A. Vaginal cabergoline in the treatment of hyperprolactinemic patients intolerant to oral dopaminergics. Fertil Steril. 1996;65(2): $440-442$.

9. Jain JK, Mishell DR Jr. A comparison of intravaginal misoprostol with prostaglandin E2 for termination of second-trimester pregnancy. N Engl J Med. 1994;331(5):290-293.

10. Coutinho EM, Coutinho EJ, Goncalves MT, Barbosa IC. Ovulation suppression in women following vaginal administration of oral contraceptive tablets. Fertil Steril. 1982;38(3):380-381.

11. Notelovitz M, Funk S, Nanavati N, Mazzeo M. Estradiol absorption from vaginal tablets in postmenopausal women. Obstet Gynecol. 2002;99(4):556-562.

12. Lete I, Dueñas JL, Esplugues JV, Martí-Cabrera M. Is the vagina an adequate route for the administration of hormonal contraceptives? Curr Drug Metab. 2010;11(10):839-849.

13. Timmer CJ, Mulders TM. Pharmacokinetics of etonogestrel and ethinylestradiol released from a combined contraceptive vaginal ring. Clin Pharmacokinet. 2000;39(3):233-242.

14. Duijkers IJ, Klipping C, Verhoeven CH, Dieben TO. Ovarian function with the contraceptive vaginal ring or an oral contraceptive: a randomized study. Hum Reprod. 2004;19(11):2668-2673.

15. Mulders TM, Dieben TO, Bennink HJ. Ovarian function with a novel combined contraceptive vaginal ring. Hum Reprod. 2002;17(10): 2594-2599.

16. Dieben TO, Roumen FJ, Apter D. Efficacy, cycle control, and user acceptability of a novel combined contraceptive vaginal ring. Obstet Gynecol. 2002;100(3):585-593.

17. Oddsson K, Leifels-Fischer B, de Melo NR, et al. Efficacy and safety of a contraceptive vaginal ring (NuvaRing) compared with a combined oral contraceptive: a 1-year randomized trial. Contraception. 2005;71(3):176-182.

18. Ahrendt HJ, Nisand I, Bastianelli C, et al. Efficacy, acceptability and tolerability of the combined contraceptive ring, NuvaRing, compared with an oral contraceptive containing 30 microg of ethinyl estradiol and $3 \mathrm{mg}$ drospirenone. Contraception. 2006;74(6):451-457.

19. Lopez LM, Grimes DA, Gallo MF, Schulz KF. Skin patch and vaginal ring versus combined oral contraceptives for contraception. Cochrane Database Syst Rev. 2008;(1):CD003552.

20. Trussell J. Contraceptive failure in the United States. Contraception. 2011;83(5):397-404.
21. Lete I, Doval JL, Pérez-Campos E, et al. Self-described impact of noncompliance among users of a combined hormonal contraceptive method. Contraception. 2008;77(4):276-282.

22. Sociedad Española de Contracepción. Update on the Clinical Management of Hormonal, Intrauterine and Emergency Contraception. Madrid: Consensus Conference, 25-26 November 2011. Available from http:// sec.es/descargas/CDC_madrid_2011_INGLES.pdf. Accessed April 2014.

23. Rosenberg MJ, Burnhill MS, Waugh MS, Grimes DA, Hillard PJ. Compliance and oral contraceptives: a review. Contraception. 1995; 52(3):137-141.

24. Milsom I, Lete I, Bjertnaes A, et al. Effects on cycle control and bodyweight of the combined contraceptive ring, NuvaRing, versus an oral contraceptive containing 30 microg ethinyl estradiol and $3 \mathrm{mg}$ drospirenone. Hum Reprod. 2006;21(9):2304-2311.

25. Oddsson K, Leifels-Fischer B, Wiel-Masson D, et al. Superior cycle control with a contraceptive vaginal ring compared with an oral contraceptive containing 30 microg ethinylestradiol and 150 microg levonorgestrel: a randomized trial. Hum Reprod. 2005;20(2): $557-562$.

26. Bjarnadóttir RI, Tuppurainen M, Killick SR. Comparison of cycle control with a combined contraceptive vaginal ring and oral levonorgestrel/ethinyl estradiol. Am J Obstet Gynecol. 2002;186(3): 389-395.

27. Sabatini R, Cagiano R. Comparison profiles of cycle control, side effects and sexual satisfaction of three hormonal contraceptives. Contraception. 2006;74(3):220-223.

28. Roumen F. Contraceptive efficacy and tolerability with a novel combined contraceptive vaginal ring, NuvaRing. Eur J Contracept Reprod Health Care. 2002;7(Suppl 2):19-24.

29. Mohamed AM, El-Sherbiny WS, Mostafa WA. Combined contraceptive ring versus combined oral contraceptive $(30-\mu \mathrm{g}$ ethinyl estradiol and 3-mg drospirenone). Int J Gynecol Obstet. 2011;114(2):145-148.

30. Roumen FJ. The contraceptive vaginal ring compared with the combined oral contraceptive pill: a comprehensive review of randomized controlled trials. Contraception. 2007;75(6):420-429.

31. Lete I, Cuesta MC, Marín JM, Guerra S. Vaginal health in contraceptive vaginal ring users - A review. Eur J Contracept Reprod Health Care. 2013;18(4):234-241.

32. Dawood MY. Primary dysmenorrhea: advances in pathogenesis and management. Obstet Gynecol. 2006;108(2):428-441.

33. Proctor ML, Roberts H, Farquhar CM. Combined oral contraceptive pill as treatment for primary dysmenorrhoea. Cochrane Database Syst Rev. 2001;(4):CD002120.

34. Lete I, Sánchez Borrego R, Haya J. [Study of the tolerability of the vaginal ring (NuvaRing ${ }^{\circledR}$ ) in contraception (ETN@)]. Prog Obstet Ginecol. 2006;49(12):695-700. Spanish.

35. Merki-Feld GS, Hund M. Clinical experience with NuvaRing in daily practice in Switzerland: Cycle control and acceptability among women of all reproductive ages. Eur J Contracept Reprod Health Care. 2007;12(3):240-247.

36. Merki-Feld GS, Hund M. Clinical experience with the combined contraceptive vaginal ring in Switzerland, including a subgroup analysis of previous hormonal contraceptive use. Eur J Contracept Reprod Health Care. 2010;15(6):413-422.

37. Brucker C, Karck U, Merkle E. Cycle control, tolerability, efficacy and acceptability of the vaginal contraceptive ring, NuvaRing: Results of clinical experience in Germany. Eur J Contracept Reprod Health Care. 2008;13(1):31-38.

38. Fait $\mathrm{T}$. [Vaginal combined contraception NuvaRing in the clinical practice in the Czech Republic]. Ceska Gynekol. 2009;74(4):286-291. Czech.

39. Creinin MD, Meyn LA, Borgatta L, et al. Multicenter comparison of the contraceptive ring and patch: a randomized controlled trial. Obstet Gynecol. 2008;111(2 Pt 1):267-277. 
40. Roumen FJ, op ten Berg MM, Hoomans EH. The combined contraceptive vaginal ring (NuvaRing): First experience in daily clinical practice in The Netherlands. Eur J Contracept Reprod Health Care. 2006;11(1):14-22.

41. Oehler MK, Rees MC. Menorrhagia: an update. Acta Obstet Gynecol Scand. 2003;82(5):405-422.

42. Abu Hashim H, Alsherbini W, Bazeed M. Contraceptive vaginal ring treatment of heavy menstrual bleeding: a randomized controlled trial with norethisterone. Contraception. 2012;85(3):246-252.

43. Dueñas JL, Lete I, Bermejo R, et al. Prevalence of premenstrual syndrome and premenstrual dysphoric disorder in a representative cohort of Spanish women of fertile age. Eur J Obstet Gynecol Reprod Biol. 2011;156(1):72-77.

44. Douglas S. Premenstrual syndrome. Evidence-based treatment in family practice. Can Fam Physician. 2002;48:1789-1797.

45. Lete I, Dueñas JL, Serrano I, et al. Attitudes of Spanish women toward premenstrual symptoms, premenstrual syndrome and premenstrual dysphoric disorder: results of a nationwide survey. Eur J Ob Gyn Reprod Biol. 2011;159(1):115-118.

46. Oddens BJ. Women's satisfaction with birth control: a population survey of physical and psychological effects of oral contraceptives, intrauterine devices, condoms, natural family planning, and sterilization among 1466 women. Contraception. 1999;59(5):277-286.

47. Caruso S, Agnello C, Intelisano G, Farina M, Di Mari L, Cianci A. Sexual behaviour of women taking low-dose oral contraceptive containing 15 mircog ethinylestradiol/60 microg gestodene. Contraception. 2004;69(3):237-240.

48. Guida M, Di Spiezio Sardo A, Bramante S, et al. Effects of two types of hormonal contraception - oral versus intravaginal - on the sexual life of women and their partners. Hum Reprod. 2005;20(4): 1100-1106.

49. Bancroft J, Tyrer G, Warner P. The assessment of sexual problems in women. Br J Sex Med. 1988;9:30-37.

50. Battaglia C, Morotti E, Persico N, et al. Clitoral vascularization and sexual behavior in young patients treated with drospirenone-ethynil estradiol or contraceptive vaginal ring: a prospective, randomized, pilot study. J Sex Med. 2014;11(2):471-480.

51. Shaw JC. Acne: effect of hormones on pathogenesis and management. Am J Clin Dermatol. 2002;3(8):571-578.

52. Arowojolu AO, Gallo MF, Lopez LM, Grimes DA, Garner SE. Combined oral contraceptive pills for treatment of acné (Review). Cochrane Database Syst Rev. 2007;(1):CD004425

53. Massai R, Mäkäräinen L, Kuukankorpi A, Klipping C, Duijkers I, Dieben $\mathrm{T}$. The combined contraceptive vaginal ring and bone mineral density in healthy pre-menopausal women. Hum Reprod. 2005;20(10): 2764-2768.

54. Massaro M, Di Carlo C, Gargano V, Formisano C, Bifulco G, Nappi C. Effects of the contraceptive patch and the vaginal ring on bone metabolism and bone mineral density: a prospective, controlled, randomized study. Contraception. 2010;81(3):209-214.

55. Verhoeven $\mathrm{CH}$, Dieben TO. The combined contraceptive vaginal ring, NuvaRing, and tampon co-usage. Contraception. 2004;69(3): 197-199.

56. Camacho DP, Consolaro ME, Patussi EV, Donatti L, Gasparetto A, Svidzinski TI. Vaginal yeast adherence to the combined contraceptive vaginal ring (CCVR). Contraception. 2007;76(6):439-443.

57. Verhoeven $\mathrm{CH}$, van den Heuvel MW, Mulders TM, Dieben TO. The contraceptive vaginal ring, NuvaRing, and antimycotic co-medication. Contraception. 2004;69:129-132.

58. Dogterom P, van den Heuval MW, Thomsen T. Absence of pharmacokinetic interactions of the combined contraceptive vaginal ring NuvaRing with oral amoxicillin or doxycycline in two randomised trials. Clin Pharmacokinet. 2005;44(4):429-438.

59. Haring T, Mulders TM. The combined contraceptive ring NuvaRing and spermicide co-medication. Contraception. 2003;67(4): 271-272.
60. Escudero FernándezJM, Rabinovich IH, Martínez de Osaba Madariaga MJ. Interference in urinary free cortisol determination by components of the NuvaRing contraceptive device. Clin Chem Lab Med. 2008;46(3): 419-420.

61. Lete I, Doval JL, Pérez-Campos E, et al. Factors affecting women's selection of a combined hormonal contraceptive method: the TEAM-06 Spanish cross-sectional study. Contraception. 2007;76(2):77-83.

62. Costa AR, Palma F, Sá JL, et al. Impact of a women's counselling programme on combined hormonal contraception in Portugal - the IMAGINE study. Eur J Contracept Reprod Health Care. 2011;16(6): 409-417.

63. Bitzer J, Gemzell-Danielsson K, Roumen F, et al. The CHOICE study: effect of counselling on the selection of combined hormonal contraceptive methods in 11 countries. Eur J Contracept Reprod Health Care. 2012;17(1):65-78.

64. Merckx M, Donders GG, Grandjean P, Van de Sande T, Weyers S. Does structured counselling influence combined hormonal contraceptive choice? Eur J Contracept Reprod Health Care. 2011;16(6): 418-429.

65. Fait T, ApetauerI . [Importance of the consultation for combined hormonal contraception's choice - results of CHOICE project in Czech and Slovak Republic]. Ceska Gynekol. 2011;76(2):140-144. Czech.

66. Gemzell-Danielsson K, Thunell L, Lindeberg M, et al. Comprehensive counseling about combined hormonal contraceptives changes the choice of contraceptive methods: results of the CHOICE program in Sweden. Acta Obstet Gynecol Scand. 2011;90(8):869-677.

67. Merki-Feld GS, Gruber IM. Intention to use a combined contraceptive method and decision after counselling in Switzerland - Swiss data from the European CHOICE study. Eur J Contracept Reprod Health Care. 2012;17(2):119-127.

68. Egarter C, Grimm C, Nouri K, Ahrendt HJ, Bitzer J, Cermak C. Contraceptive counselling and factors affecting women's contraceptive choices: results of the CHOICE study in Austria. Reprod Biomed Online. 2012;24(7):692-697.

69. Lete I, Pérez-Campos E, Correa M, et al. Continuation rate of combined hormonal contraception: a prospective multicenter study. J Womens Health. 2012;21(5):490-495.

70. Novak A, de la Loge C, Abetz L, van der Meulen EA. The combined contraceptive vaginal ring, NuvaRing: an international study of user acceptability. Contraception. 2003;67(3):187-194.

71. Martínez F, Ramírez I, Pérez-Campos E, Latorre K, Lete I. Venous and pulmonary thromboembolism and combined hormonal contraceptives. Systematic review and meta-analysis. Eur J Contracept Reprod Health Care. 2012;17(1):7-29.

72. Lidegaard O, Nielsen LH, Skovlund CW, Lokkegaard E. Venous thrombosis in users of non-oral hormonal contraception: follow-up study, Denmark 2001-10. BMJ. 2012;344:e2990.

73. Tchaikovski SN, Rosing J. Mechanisms of estrogen-induced venous thromboembolism. Thromb Res. 2010;126(1):5-11.

74. Magnusdóttir EM, Bjarnadóttir RI, Önundarson PT, et al. The contraceptive vaginal ring (NuvaRing) and hemostasis: a comparative study. Contraception. 2004;69(6):461-467.

75. van den Heuvel MW, van Bragt AJ, Alnabawy AK, Kaptein MC. Comparison of ethinylestradiol pharmacokinetics in three hormonal contraceptive formulations: the vaginal ring, the transdermal patch and an oral contraceptive. Contraception. 2005;72(3):168-174.

76. Jensen JT, Burke AE, Barnhart KT, Tillotson C, MesserleForbes M, Peters D. Effects of switching from oral to transdermal or transvaginal contraception on markers of thrombosis. Contraception. 2008;78(6):451-458.

77. Sidney S, Cheetham TC, Connell FA, et al. Recent combined hormonal contraceptives (CHCs) and the risk of thromboembolism and other cardiovascular events in new users. Contraception. 2013;87(1):93-100.

78. Dinger J, Möhner S, Heinemann K. Cardiovascular risk associated with the use of an etonogestrel-containing vaginal ring. Obstet Gynecol. $2013 ; 122(4): 800-808$ 


\section{Publish your work in this journal}

Open Access Journal of Contraception is an international, peerreviewed, open access, online journal, publishing original research, reports, reviews and commentaries on all areas of contraception. In addition to clinical research, demographics and health-related aspects, the journal welcomes new findings in animal and preclinical studies

relating to understanding the biological mechanisms and practical development of new contraceptive agents. The manuscript management system is completely online and includes a very quick and fair peer-review system. Visit http://www.dovepress.com/testimonials.php to read real quotes from published authors.

Submit your manuscript here: http://www.dovepress.com/open-access-journal-of-contraception-journal 